\title{
Doppler microembolic load predicts risk of thromboembolic complications in Novacor patients
}

\author{
Darius G. Nabavi, MD ${ }^{\mathrm{a}}$ \\ Joerg Stockmann, MDa \\ Christof Schmid, MD \\ Michael Schneider, MD ${ }^{b}$ \\ Dieter Hammel, MD ${ }^{\mathrm{b}}$ \\ Hans H. Scheld, MD ${ }^{\text {b }}$ \\ E. Bernd Ringelstein, MD ${ }^{a}$
}

Objective: Left ventricular assist devices have become an established method to bridge patients with end-stage cardiac failure to heart transplantation. Besides infection and bleeding, thromboembolism represents one of the most serious complications. We evaluated the value of microembolic signals in predicting thromboembolic events for individual patients and distinctive left ventricular assist device periods.

Methods: Twenty patients (14 male) aged 23-57 years supported with the Novacor N100 left ventricular assist device were enrolled in this study. All patients were on effective anticoagulation, 12 patients additionally received antiplatelet therapy. Unilateral detection of microembolic signals was performed once weekly by insonation of the middle cerebral artery using transcranial Doppler sonography for 30 minutes duration. Evidence of clinically manifest thromboembolic events was based on regular questionnaires, clinical examinations, and results of diagnostic procedures.

Results: During a cumulative follow-up of 3876 left ventricular assist device days, 44 thromboembolic complications occurred (incidence, 1.1\%) in 15 out of 20 patients. A total of 360 transcranial Doppler sonography monitorings (range, 5-34 per patient) were performed with an overall microembolic signals prevalence of $35.3 \%$ and a microembolic signal mean of $2.3 \pm 9.2$ per examination. There was a highly significant correlation between the individual microembolic signal activity and the respective incidence of clinical thromboembolism $(r=0.61-0.9 ; P<.01)$. Patients with additional antiplatelet treatment had significantly less thromboembolic complications $(0.7 \%)$ and lower microembolic signal prevalence (18.3\%) than those without (2.8\% and 65.4\%, respectively). Individual patients and left ventricular assist device months with clinical thromboembolization could be identified using the microembolic signal activity with moderate positive $(0.37-0.7)$ and high negative predictive values $(0.82-1.0)$.

Conclusions: The amount of microembolic signals, serially detected in patients with the Novacor left ventricular assist device, is significantly associated with their incidence of embolic complications. The high negative predictive value of microembolic signals enables to identify those patients and left ventricular assist device periods with particularly low risk of clinical thromboembolization.

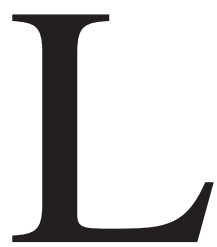

eft ventricular assist devices (LVAD) are external systems implanted to support or entirely take over the mechanical function of the impaired left ventricle. ${ }^{1}$ Technical advances have enabled for better patient mobility and life quality, ${ }^{2}$ allowing their use even in an outpatient setting. ${ }^{3,4}$ Currently, LVAD are predominantly used in patients with severe irreversible cardiac dysfunction as a bridge to heart transplantation. ${ }^{5-9}$ Moreover, it has been shown that in a subgroup of patients, 
the temporary use of LVAD can facilitate the recovery of the native heart to regain normalized function. ${ }^{10-13}$ The still-widening gap between patients awaiting cardiac transplantation and the number of available donor organs ${ }^{14,15}$ has even raised the question of whether LVAD can be used as a permanent treatment option for end-stage heart failure. ${ }^{3}$

Nevertheless, various types of complications still represent major restrictions to widespread application of LVAD. Besides infection and bleeding, thromboembolism represents one of the most serious complications during LVAD use. $^{1,6,9,16,17}$ However, frequencies of thromboembolic events differ greatly among individual patients and different types of LVAD. ${ }^{16-20}$ This raises the question about etiology and pathomechanism of LVAD-associated thromboembolisms as well as their appropriate prevention. Diagnostic tools that enable the distinguishing of patients at low risk from those at high risk of thromboembolization may allow for individually tailored treatment strategies and may help to identify the subgroup of patients most suitable for permanent LVAD use.

During recent years, it has been recognized that microembolic signals (MES) are detectable noninvasively by transcranial Doppler sonography (TCD) in various patient groups suffering from stroke $\mathrm{e}^{21-23}$ or prone to cerebral ischemia. ${ }^{24-31}$ In a preliminary study on 6 patients followed by daily TCD studies, we have reported on a significant correlation between the number of MES and the incidence of thromboembolization during the first 30 days after LVAD implantation. ${ }^{32}$ In this paper we present results of the longterm follow-up of 20 patients supported by the Novacor N100 LVAD. The aim of this study was to answer the following questions: (1) Do MES represent prognostic markers that reflect the individual risk of clinical thromboembolization? (2) Do MES correlate with type and intensity of antithrombotic treatment?

\section{Methods \\ Subjects}

From 1994 to November 1998, 20 patients who underwent implantation of the Novacor N100 LVAD (Baxter Healthcare Corp., Novacor Div., Oakland, Calif) were enrolled in this study. After the purpose and protocol of this study was explained comprehensively, all patients gave informed consent. The patients suffered from dilated cardiomyopathy $(\mathrm{n}=11)$, chronic ischemic heart disease $(n=8)$, and postpartum cardiomyopathy $(n=1)$. The LVAD implantation procedure and perioperative management has been described elsewhere. ${ }^{16,33}$ Except for patient 2 (50\%-60\% stenosis of the left carotid artery), no patient had a stenosis of the carotid arteries $>50 \%$ as assessed by extracranial Doppler sonography and/or intraarterial angiography. Coagulation abnormalities had been excluded by laboratory investigations. A minimum of 4 repetitive TCD monitorings was required for inclusion into the statistical analysis. Therefore, 3 further patients in whom TCD examinations were performed once $(n=2)$ or twice $(n=1)$ only during the entire LVAD period were excluded.

\section{Antihemostatic Treatment}

Postoperatively, all patients were effectively anticoagulated using heparin (target activated partial thromboplastin time, 60-80 s). After stabilization of the clinical situation, oral anticoagulation using phenprocoumon was started (target International Normalized Ratio, 2.0-3.5). Additionally, from patient 9 on, antihemostatic treatment was supplemented by administration of platelet aggregation inhibitors (330 mg ASS plus $75 \mathrm{mg}$ dipyridamole 3 times daily). Six patients were discharged from hospital while on LVAD and were seen every other week in the outpatient clinic. In some patients (e.g., ambulatory, long-term LVAD use) blood was drawn only once or twice weekly to measure the coagulation status. In these patients, attempt was made to synchronize MES-monitoring and coagulation tests. If no blood was drawn on the day of the TCD examination, the blood test closest to this TCD examination was taken for further statistical analysis.

\section{Microemboli Monitoring}

Repetitive 30-minute MES monitorings were performed using a commonly available TCD machine (TC 4040; EME/Nicolet, Kleinostheim, Germany). The mainstem of the middle cerebral artery was unilaterally identified through the temporal skull in a depth of 45 to $55 \mathrm{~mm}$. The first patients (Nos. 1-7) underwent TCD monitorings using a single-channel ultrasound probe. From patient 8 on, simultaneous 2-channel MES monitorings were performed in depths of 45-50 $\mathrm{mm}$ and 55-60 $\mathrm{mm}$ with an interchannel distance kept at $10 \mathrm{~mm}$. The sample volume was set at $10 \mathrm{~mm}$. By means of this 2-channel approach, true MES (ie, time delay of the signal appearance in accordance with the flow direction from the proximal to the distal channel) could be distinguished from artifact signals, e.g., due to external manipulations at the probe (ie, simultaneous appearance of the signal within both channels). ${ }^{34,35}$ The probe was fixed on the head by an elastic band to maintain the insonation position and to avoid movement artifacts. The sonographical data were processed using a 128-point fast-Fouriertransformation with a time window overlap of at least $50 \%$. During the entire monitoring period, an experienced investigator was present to watch for patient movements and to detect MES acoustically on-line. Additionally, the MES detection software of the TCD machine was used with a detection threshold of $>7$ decibels. Off-line reanalysis of the automatically stored signals was performed later by an experienced observer. Identification of MES was in accordance with recent consensus statements. ${ }^{35,36}$ Attempt was made to perform MES monitorings once weekly until the endpoint (transplantation or death) was reached. In cases of severely unstable clinical situations and/or reduced patient cooperation, TCD examamination was postponed until appropriate conditions were regained. In ambulatory patients, TCD monitorings were performed on the days of clinical follow-up. In our pilot series (ie, patients 1-6), ${ }^{32}$ subjects had been examined daily during the first month on LVAD support. To avoid statistical bias, only 1 TCD examinations per week from this period was included in the overall statistical analysis that had been randomly selected from the daily studies.

Before each TCD examination, a standardized questionnaire was performed to disclose clinically manifest cerebral thromboembolic events (e.g., transient focal loss of vision, sensory, motor functions or speech disturbances). Furthermore, evidence of pe- 
TABLE 1. Survey of the clinical characteristics and results of repetitive MES-monitoring

\begin{tabular}{|c|c|c|c|c|c|c|c|c|c|c|c|}
\hline \multicolumn{5}{|c|}{ Basic characteristics } & \multicolumn{4}{|c|}{ Treatment and clinical course } & \multicolumn{3}{|c|}{ MES monitoring } \\
\hline No. & Age & Sex & $\begin{array}{l}\text { Primary } \\
\text { heart } \\
\text { disease }\end{array}$ & $\begin{array}{l}\text { Duration of } \\
\text { LVAD use } \\
\text { (d) }\end{array}$ & $\begin{array}{c}\text { Effective } \\
\text { anticoagulation* } \\
(\%)\end{array}$ & $\begin{array}{c}\text { Antiplatelet } \\
\text { treatment }\end{array}$ & $\begin{array}{c}\text { Embolic events } \\
\mathbf{n}(\%)\end{array}$ & Outcome & $\begin{array}{l}\text { No. of } \\
\text { exams }\end{array}$ & $\begin{array}{l}\text { Prevalence } \\
\text { of MES (\%) }\end{array}$ & $\begin{array}{c}\text { Mean } \pm \text { SD } \\
\text { of MES }\end{array}$ \\
\hline 1 & 23 & $\mathrm{~F}$ & PPCM & 161 & 92 & No & $10(6.2)$ & HTX & 24 & 95.8 & $5.5 \pm 3.8$ \\
\hline 2 & 53 & $\mathrm{M}$ & ICM & 159 & 78 & No & $1(0.6)$ & HTX & 20 & 5 & $0.2 \pm 0.7$ \\
\hline 3 & 37 & $M$ & DCM & 109 & 81 & No & $1(0.9)$ & $\dagger$ & 16 & 50 & $2.3 \pm 3.2$ \\
\hline 4 & 55 & $\mathrm{M}$ & ICM & 27 & 72 & No & $5(18.5)$ & $t$ & 4 & 100 & $60.3 \pm 63$ \\
\hline 5 & 35 & $M$ & DCM & 161 & 84 & No & $0(0)$ & HTX & 17 & 64.7 & $1.2 \pm 1.2$ \\
\hline 6 & 51 & $M$ & ICM & 171 & 96 & No & $5(4.4)$ & HTX & 17 & 94.1 & $4.1 \pm 3.6$ \\
\hline 7 & 29 & $M$ & DCM & 135 & 84 & No & $2(1.5)$ & HTX & 21 & 81 & $4.3 \pm 4.7$ \\
\hline 8 & 26 & $\mathrm{~F}$ & DCM & 85 & 97 & No & $1(1.2)$ & HTX & 9 & 33.3 & $0.8 \pm 1.4$ \\
\hline 9 & 43 & $M$ & ICM & 237 & 85 & Yes & $2(0.9)$ & HTX & 31 & 6.5 & $0.1 \pm 0.3$ \\
\hline 10 & 33 & $M$ & DCM & 291 & 91 & Yes & $4(1.4)$ & HTX & 31 & 16.1 & $0.5 \pm 1.8$ \\
\hline 11 & 34 & $M$ & DCM & 309 & 88 & Yes & $0(0)$ & HTX & 34 & 11.8 & $0.2 \pm 0.5$ \\
\hline 12 & 47 & $M$ & DCM & 272 & 91 & Yes & $8(2.9)$ & HTX & 22 & 36.6 & $1.3 \pm 2.6$ \\
\hline 13 & 37 & $\mathrm{~F}$ & ICM & 33 & 73 & Yes & $0(0)$ & $t$ & 5 & 0 & $0 \pm 0$ \\
\hline 14 & 42 & $\mathrm{~F}$ & DCM & 421 & 84 & Yes & $1(0.2)$ & HTX & 23 & 0 & $0 \pm 0$ \\
\hline 15 & 47 & $M$ & ICM & 175 & 91 & Yes & $0(0)$ & HTX & 17 & 41.2 & $1.4 \pm 2.0$ \\
\hline 16 & 57 & $M$ & ICM & 70 & 77 & Yes & $2(2.9)$ & $\dagger$ & 8 & 75 & $16.6 \pm 15.0$ \\
\hline 17 & 34 & $\mathrm{M}$ & DCM & 214 & 64 & Yes & $1(0.5)$ & HTX & 16 & 25 & $0.5 \pm 1.0$ \\
\hline 18 & 38 & $\mathrm{~F}$ & $\mathrm{DCM}$ & 224 & 92 & Yes & $0(0)$ & HTX & 14 & 14.3 & $0.1 \pm 0.4$ \\
\hline 19 & 51 & $M$ & $\mathrm{DCM}$ & 298 & 84 & Yes & $1(0.3)$ & HTX & 21 & 14.3 & $0.2 \pm 0.5$ \\
\hline 20 & 51 & $M$ & ICM & 324 & 74 & Yes & $0(0)$ & $\dagger$ & 10 & 30 & $0.4 \pm 0.7$ \\
\hline
\end{tabular}

F, Female; $M$, male; HTX, heart transplant; PPCM, postpartum cardiomyopathy; ICM, ischemic cardiomyopathy; DCM, dilated cardiomyopathy. *Effective anticoagulation is given as the percentage of blood tests demonstrating target values as stated in the Methods section. tDenotes death.

ripheral and cerebral thromboembolic complications was based on the regularly screened medical records and patient files. In cases of cerebral or peripheral thromboembolism, results of the respective diagnostic procedures (e.g., computed tomography of the head, angiography of the abdominal or peripheral arteries) were noted.

\section{Statistics}

All statistical analyses were done using SPSS 9.0 for Windows (SPSS Inc., Chicago, Ill). Descriptive statistics were done using standard parameters such as mean \pm standard deviation (SD), and maximum and minimum values. For non-normally distributed data, comparisons of 2 and more groups were performed using the Mann-Whitney and the Kruskal-Wallis tests. Frequency distributions were statistically assessed by $\chi^{2}$ analysis (with Yates correction if necessary). Linear regression analysis and Pearson Product Moment test were used to evaluate correlations between 2 parameters. The sensitivity, specificity, and the positive (PPV) and negative predictive values (NPV) of MES results were calculated with respect to occurrence of thromboembolic events. Two approaches were used to calculate the predictive values. First, the patients' frequency of thromboembolic complications was taken as the outcome parameter. This analysis was therefore based on the data of 20 individuals. Secondly, the period on LVAD support was divided by months (ie, 30-day periods) into separate units. Only if the residue of days was $>20$ and at least 2 TCD examinations had been been performed, this period was statistically included as another LVAD month. This led to 117 months on LVAD support, 25 of which were symptomatic (ie, at least 1 embolic complica- tion) or asymptomatic (ie, no embolism within this month). Receiver-operating characteristic (ROC) curves for MES means and MES prevalences were analyzed and compared statistically. ${ }^{37}$

\section{Results}

Basic characteristics of the 20 patients are given in Table 1. The mean $( \pm$ SD) duration of LVAD support was $194 \pm$ 104 days (range, 23-421 days). Five patients died from multiorgan failure $(\mathrm{n}=1)$, recurrent thromboembolism with bleeding $(n=2)$, right heart $(n=1)$, and chronic respiratory failure $(\mathrm{n}=1)$. The other 15 patients reached heart transplantation. In $84.7 \%$ of days during LVAD support, patients were effectively anticoagulated (range, 64\%97\%). During a cumulative follow-up at 3876 days on LVAD support, 44 thromboembolic complications occurred in 14 patients. This led to an overall incidence of 1.1 clinical embolic events per 100 LVAD-days. Six of the 20 patients (30\%) remained asymptomatic during the entire LVAD support. Embolic complications affected the cerebral circulation in $28(63.6 \%)$, the retinal in $5(11.4 \%)$, and the peripheral vessel system in 11 cases $(25 \%)$. Transient symptoms occurred in $32(72.7 \%)$, persisting deficits or manifest organ damage resulted in the remaining 12 cases $(27.3 \%)$. On cranial CT, ischemic brain infarctions were observed following 11 out of $28(39.3 \%)$ cerebral embolic events. Remarkably, 5 out of 6 asymptomatic patients were on 
TABLE 2. Comparison of LVAD patients with regard to occurrence of thromboembolic complications and antiplatelet therapy

\begin{tabular}{|c|c|c|c|c|c|c|}
\hline & \multicolumn{3}{|c|}{ Thromboembolic complications } & \multicolumn{3}{|c|}{ Antiplatelet therapy* } \\
\hline & Yes & No & $P$ value & Yes & No & $P$ value \\
\hline No. of patients & 14 & 6 & - & 12 & 8 & - \\
\hline Mean age & 41.5 & 40.3 & 0.8 & 42.8 & 38.6 & .80 \\
\hline Mean ( $\pm S D$ ) LVAD duration & $189 \pm 107$ & $204 \pm 107$ & 0.8 & $239 \pm 108$ & $126 \pm 50$ & .01 \\
\hline Prevalence of thromboembolism (\%) & 1.7 & 0 & $<.001$ & 0.7 & 2.5 & $<.001$ \\
\hline MES prevalence $(\%)$ & 38.5 & 25.7 & .02 & 18.3 & 65.4 & $<.001$ \\
\hline MES mean $( \pm S D)$ & $2.94 \pm 10.8$ & $0.53 \pm 1.12$ & .02 & $0.9 \pm 4.1$ & $4.7 \pm 14.3$ & $<.001$ \\
\hline
\end{tabular}

${ }^{*}$ Antiplatelet therapy consisted of a fixed combination of acetacetylate acid $(330 \mathrm{mg})$ plus dipyridamole $(75 \mathrm{mg})$ given 3 times daily.

antiplatelet therapy as compared with only half of the 14 symptomatic patients $(P=.30$, Fisher's exact test). Thus, patients with platelet inhibitors had a significantly lower incidence of clinical thromboembolism $(0.7 \%)$ as compared to those patients without antiplatelet therapy $(2.5 \%, P<$ .001). In contrast, there was no statistical association between frequency of effective anticoagulation and occurrence of thromboembolism $(P=.80)$.

A survey of the TCD results is also given in Table 1. A total of 360 TCD monitorings (range, 5-34 per patient) were performed. This led to an average examination rate of 1 TCD monitoring every 10.2 days. MES were detected in 127 examinations (35.3\%), with only 2 patients (10\%) remaining without any MES on repetitive examinations (see Table 1). The overall mean MES number per monitoring was $2.3 \pm 9.2$ (range, 0-154). There was a significant correlation between prevalence and mean counts of MES ( $r$ $=0.96, P<.001)$. We compared the 14 patients with, and the 6 patients without, occurrence of thromboembolic complications (see Table 2). Symptomatic patients had a significantly higher prevalence (38.5\%) and higher mean counts of MES (2.94) as compared with asymptomatic subjects ( $25.7 \%$ and 0.53 , respectively). We did not find any statistical correlation between the MES activity with either the patient's size $(r=0.04 ; P=.80)$, body mass index $(r=$ $0.10 ; P=.90)$, or age $(r=0.06, P=.80)$.

Linear regression analysis revealed a highly significant correlation between the individual MES activity and the respective incidence of clinical thromboembolism. This was true for both mean MES counts and the individual MES prevalence (Table 3, Fig. 1). Because patient 4 had both a high incidence of embolic complications and extremely high MES activity (see Table 1), analysis was significantly influenced by this single subject. Therefore, analysis was repeated after exclusion of this subject. The resulting correlation factors were lower but still statistically significant (Table 3). On postmortem examination, patient 4 had extended thrombus formation at the level of the LVAD outflow valves, which may have caused the high rate of thromboembolic complications.
TABLE 3. Results of Pearson Product Moment analysis between the MES-activity and the risk of thromboembolic complications

\begin{tabular}{lcc}
\hline & $\begin{array}{c}\text { Correlation } \\
\text { factor }\end{array}$ & $\boldsymbol{P}$ value \\
\hline All 20 patients included & & \\
MES & & \\
$\quad$ Mean & 0.91 & $<.001$ \\
$\quad$ Median & 0.87 & $<.001$ \\
$\quad$ Prevalence & 0.61 & .004 \\
After exclusion of patient 4 & & \\
MES & & .02 \\
$\quad$ Mean & 0.51 & .03 \\
Median & 0.47 & .003 \\
$\quad$ Prevalence & 0.64 & \\
\hline
\end{tabular}

We calculated the predictive value of the patients MES activity with respect to the individual embolic complication rate. As MES cut-off value, we chose the median of all average values providing groups of similar numbers. Therefore, we analyzed the predictive value for an individual MES mean of $>0.5$ per monitoring and for an individual MES prevalence of $>30 \%$. Two outcome cut-offs were used: (1) evidence of any thromboembolic complication (ie, incidence $>0 \%$ throughout LVAD support), distinguishing 16 symptomatic from 4 asymptomatic patients; (2) incidence of thromboembolic complications $>1.1 \%$ (ie, average incidence of thromboembolism), distinguishing 12 patients with higher-than-average, from 8 patients with lower-than-average, complication rates. Table 4 summarizes the results of the statistical analysis. NPV were consistently higher (0.82-1.0) than PPV (0.36-0.7). Moreover, PPV and NPV were higher when using the $1.1 \%$ complication rate as the cut-off than in distinguishing patients with from those without any embolic complication (Table 4). ROC curve comparison did not reveal a significant difference between the predictive value of the MES mean and the MES prevalence for both of the outcome dividers $(P>.80)$. Finally, the threshold of $>0.5$ MES per TCD monitoring was ap- 


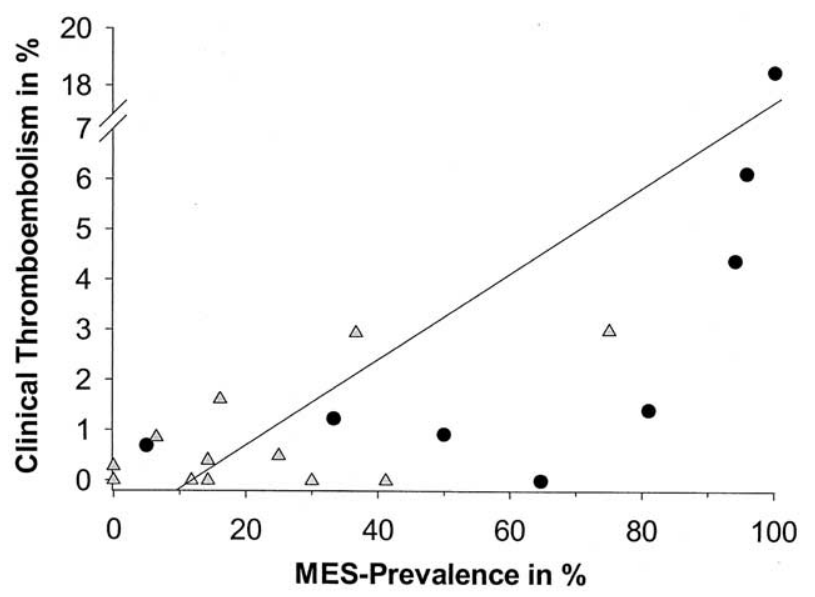

Figure 1. Regression analysis between individual MES-prevalence (X-axis) and incidence of thromboembolic complications (Y-axis). The symbols represent patients without (solid circle) and with antiplatelet therapy (open triangle). For clarity, a break was introduced to the Y-axis owing to the high incidence of embolic complications $(18.5 \%)$ of patient 4 . The line represents the regression line.

plied to the 117 LVAD-months with respect to its predictive value. Months with occurrence of clinical embolic events could be predicted with moderate values for sensitivity (52\%) and PPV (0.62) but high values for specificity (91\%) and NPV (0.87).

\section{Discussion}

In a previous study on 6 patients supported with the Novacor LVAD followed for 30 days, we reported on a significant correlation between the daily MES activity and the clinical manifestation of thromboembolism. ${ }^{32}$ In this pilot series, both incidence of embolic complications $(6.7 \%)$ and prevalence of MES (84.1\%) were high without any correlation to type or intensity of antihemostatic treatment. Here, we present our long-term results including 20 patients cumulating to a follow-up of approximately 10 years on LVAD support. In contrast to our earlier report, MES activity was much less, with an average prevalence of $35 \%$ and mean value of only 2.3 per TCD examination. Interestingly, the incidence of thromboembolic complications has likewise declined more than 5 times, down to 1.1 embolic events per 100 days. Thus, the association between subclinical microemboli and clinically manifest macroembolization, although on a lower level, remains apparent. In consequence, a highly significant correlation between MES activity and risk of embolic complications was confirmed in the present study $(r=0.61-0.92, P<.01)$.

Clarification for the large difference with regard to micro- and macroembolization between this and our previous study $^{32}$ provides a comparison between the first 8 patients and the following 12 patients. Whereas the latter group received acetylsalicylic acid $(330 \mathrm{mg})$ and dipyridamol $(75$ $\mathrm{mg}) 3$ times daily in addition to anticoagulation, the former group received anticoagulation only. MES prevalence was more than 3 times and MES mean counts were more than 5 times higher in the group without platelet inhibitors. Similarly, the incidence of embolic complications was 4 times higher in patients without, than in the patients with, antiplatelet treatment. This suggests that use of platelet inhibitors as an adjunct to anticoagulant therapy can sufficiently suppress the microembolic activity and thromboembolism as well. Schmid and colleagues ${ }^{38}$ reported on significantly less thromboembolic complications with use of platelet inhibitors in patients with Novacor LVAD. Growing experience with this LVAD type with respect to surgical technique and postoperative management may have further contributed to this positive trend.

Irrespective of its cause, the large inter-individual variability of clinical events in our series allowed investigation of the diagnostic value of MES over a wide range of embolic complication rates (incidence, $0-18.5 \%$ ). Remarkably, correlation factors between clinical and TCD data remained significant even after excluding the patient (No. 4) with extreme values most favorably influencing the data. In this respect, however, MES prevalence was more stable than average MES counts. We further evaluated the diagnostic value of MES to identify patients with any embolic complication or those with an incidence of clinical embolism above the overall average (ie, $1.1 \%)$. Since the latter approach generated groups of similar size, higher predictive values were provided (0.7-1) as compared with the former approach (0.36-0.82). Overall, NPV of MES appeared to be consistently higher than PPV. According to our data, patients with average MES prevalences of $<30 \%$ or with MES means of $<0.5$ had a $>80 \%$ likelihood not to develop any embolic complication and a $>90 \%$ likelihood to remain below the average complication rate of $1.1 \%$. Thus, MES enable to identify patients with a lower-than-average risk of thromboembolization. However, it needs to be emphasized that this result is based on the MES profiles assessed by repetitive and not by single TCD monitorings. Intermittent peak counts of MES (e.g., $>100$ per examination) do not "announce" incipient stroke as has been reported in other clinical situations. ${ }^{39}$ A high-MES profile rather indicates a mild prothrombotic state, constituting the basis on which thrombus formation and subsequent embolism may occur. The optimum frequency of TCD monitorings yielding reliable MES profiles has not been defined yet. Our long-term results demonstrate that TCD examinations every 7-10 days reveal results as predictive and reliable as the daily measurements in our pilot series. As this frequency appeared to be practical even for ambulatory patients, we recommend it for clinical use in this patient group. 
TABLE 4. Results of ROC curve analysis for MES mean and MES prevalence to predict thromboembolic events

\begin{tabular}{|c|c|c|c|c|}
\hline & $\begin{array}{l}\text { Sensitivity (95\% } \\
\text { CI) }\end{array}$ & $\begin{array}{l}\text { Specificity }(95 \% \\
\text { CI) }\end{array}$ & PPV & NPV \\
\hline \multicolumn{5}{|c|}{ Patients' complication rate $>0 \%$} \\
\hline MES mean $>0.5$ & $64.3(35.2-87.1)$ & $66.7(22.7-94.7)$ & 0.39 & 0.85 \\
\hline MES prevalence $>30 \%$ & $57.1(28.9-82.2)$ & $66.7(22.7-94.7)$ & 0.36 & 0.82 \\
\hline \multicolumn{5}{|c|}{ Patients' complication rate $>1.1 \%$} \\
\hline MES mean $>0.5$ & $100(100-100)$ & $75.0(42.8-94.2)$ & 0.73 & 1.0 \\
\hline MES prevalence $>30 \%$ & $87.5(47.4-97.9)$ & $75.0(42.8-94.2)$ & 0.70 & 0.90 \\
\hline
\end{tabular}

$\mathrm{Cl}, 95 \%$ confidence interval. Two clinical cutoff values were chosen: (1) evidence of any embolic complication (>0\%) and (2) above-average embolic complications $(>1.1 \%)$.

Other issues still to be solved are mode of generation and structural composition of the microparticles causing MES when insonated by TCD. As has been demonstrated, cavitation processes at the rims of prosthetic cardiac valves can cause gaseous microbubbles and are responsible for most MES in these patients. ${ }^{40}$ However, much lower rates of MES are detectable in porcine or bovine valve prosthesis, ${ }^{41,42}$ which are used in the Novacor LVAD. We further found a significant association between the MES load and treatment with platelet inhibitors. So far, reduced MES activity with antiplatelet treatment has only been reported by Goertler and colleagues ${ }^{43}$ in patients symptomatic carotid artery stenosis presumed to be of thrombotic structure. Therefore, we believe that at least part of microemboli detected in our Novacor patients are of solid nature caused by microthrombi. We are currently investigating this issue using the oxygen inhalation technique. ${ }^{44}$ Latest developments with novel algorithms of raw data analysis of the TCD signal will allow identification of the structural composition of MES on-line in the near future. ${ }^{45}$ This may help to approximate an ultimate goal of MES detection, which is to noninvasively monitor the effectiveness of various antihemostatic therapies. Thereby, individually tailored treatment strategies with optimum risk-benefit ratio could be realized.

Surprisingly, still limited studies on MES detection in LVAD patients have been published so far. Knepper and colleagues $^{46}$ reported on MES with numbers of up to 180 per minute(!) in various types of LVAD, while half of the patients suffered from embolic complications. Roberts and colleagues ${ }^{47}$ reported on MES detection in patients with the Thermo Cardiosystems 1000 IP Heartmate LVAD. They found a very low amount of MES (prevalence, 26\%; mean, 0.54 ) and an equally low incidence of clinical thromboembolization $(\sim 0.1 \%)$. Recently, Potapov and colleagues ${ }^{48}$ reported an absence of MES in 5 patients supported with the novel DeBakey LVAD, which is believed to be of low thrombogenicity. Interestingly, their negative MES findings were accompanied by complete absence of clinically embolic events. Results of the above studies, although limited, show a consistent trend toward enhanced MES activity in patients with high risk of clinical embolism and vice versa. This finding further supports our hypothesis that the amount of MES in LVAD patients reflects their individual thromboembolic activity and therefore quantifies proneness to thromboembolic complications. Thus, there is hope that TCD monitoring could help to establish an individually "tailored" antihemostatic treatment based on the actual and individual risk profile. The latter may replace the current therapeutic strategy, which is more rigid and does not sufficiently account for the inter-individually heterogeneous incidence and risk of thromboembolic complications. Thereby, the therapeutic dilemma between thromboembolisms on the one hand, and bleeding complications on the other, could be solved.

In summary, our long-term experience with repetitive TCD monitorings in 20 patients supported with the Novacor LVAD underscores the diagnostic potential of MES. The high NPV of MES enables to identify especially patients at low risk of thromboembolic complications, which could guide therapeutic decisions. More recently, permanent LVAD use is now under discussion as a definitive alternative to heart transplantation. ${ }^{35,36}$ With this regard, a low level of MES activity on repetitive TCD monitorings, indicating a reduced risk of future thromboembolic complications, could become an additional selection criterion for this specific indication in the near future. The association of MES activity to type of antithrombotic treatment opens further diagnostic perspectives for this clientele. We hope the present results will encourage other groups to investigate the relevance of Doppler MES in LVAD patients.

\section{References}

1. Goldstein DJ, Oz MC, Rose E. Implantable left ventricular assist devices. N Engl J Med. 1998;339:1522-33.

2. Moskowitz AJ, Weinberg AD, Oz MC, Williams DL. Quality of life with an implanted left ventricular assist device. Ann Thorac Surg. 1997;64:1764-9.

3. Catanese KA, Goldstein DJ, Williams DL, Foray AT, Illick CD, Gardocki MT, et al. Outpatient left ventricular assist device support: a new destination rather than a bridge. Ann Thorac Surg. 1996;62:64652

4. DeRose JJ Jr, Umana JP, Argenziano M, Catanese KA, Gardocki MT, Flannery M, et al. Implantable left ventricular assist devices provide an excellent outpatient bridge to transplantation and recovery. J Am Coll Cardiol. 1997;30:1773-7. 
5. Vetter HO, Kaulbach HG, Schmitz C. Experience with the Novacor left ventricular assist system as a bridge to cardiac transplantation, including the new wearable system. J Thorac Cardiovasc Surg. 1995; 109:74-80.

6. Koul B, Solem JO, Steen S, Casimir-Ahn H, Granfeldt H, Lonn UJ. HeartMate left ventricular assist device as bridge to heart transplantation. Ann Thorac Surg. 1998;65:1625-30.

7. McCarthy PM. HeartMate implantable left ventricular assist device: bridge to transplantation and future applications. Ann Thorac Surg. 1995;59(Suppl 2):S46-51.

8. Portner PM, Oyer PE, Pennington DG, Baumgartner WA, Griffith BP, Frist WR, et al. Implantable electrical left ventricular assist system: bridge to transplantation and the future. Ann Thorac Surg. 1989;47: 142-50.

9. McCarthy PM, Portner PM, Tobler HG, Starnes VA, Ramasamy N, Oyer PE. Clinical experience with the Novacor ventricular assist system. Bridge to transplantation and the transition to permanent application. J Thorac Cardiovasc Surg. 1991;102:578-86.

10. Lee SH, Doliba N, Osbakken M, Oz M, Mancini D. Improvement of myocardial mitochondrial function after hemodynamic support with left ventricular assist devices in patients with heart failure. $J$ Thorac Cardiovasc Surg. 1998;116:344-9.

11. Mueller J, Wallukat G, Weng YG, Dandel M, Spiegelsberger S, Semrau S, et al. Weaning from mechanical cardiac support in patients with idiopathic dilated cardiomyopathy. Circulation. 1997; 96:542-9.

12. Dipla K, Mattiello JA, Jeevanandam V, Houser SR, Margulies KB. Myocyte recovery after mechanical circulatory support in humans with end-stage heart failure. Circulation. 1998;97:2316-22.

13. Pietsch L, Laube H, Baumann G, Konertz W. Recovery from end-stage ischemic cardiomyopathy during long-term LVAD support. Ann Thorac Surg. 1998;66:555-7.

14. Allen MD, Fishbein DP, McBride M, Ellison M, Daily OP. Who gets a heart? Rationing and rationalizing in heart transplantation. West J Med. 1997;166:326-36.

15. Evans RW, Manninen DL, Garrison LP Jr, Maier AM. Donor availability as the primary determinant of the future of heart transplantation. JAMA. 1986;255:1892-8.

16. Schmid C, Weyand M, Nabavi DG, Hammel D, Deng MC, Ringelstein $\mathrm{EB}$, et al. Cerebral and systemic embolization during left ventricular suport with the Novacor N100 device. Ann Thorac Surg. 1998;65: 1703-10.

17. Spanier TB, Oz MC, Levin H, Weinberg A, Stamatis K, Stern D, et al. Activation of coagulation and fibrinolytic pathways in patients with left ventricular assist devices. J Thorac Cardiovasc Surg. 1996;112: 1090-7.

18. Slater JP, Rose EA, Levin HR, Frazier OH, Roberts JK, Weinberg AD, et al. Low thromboembolic risk without anticoagulation using advanced-design left ventricular assist devices. Ann Thorac Surg. 1996; 62:1321-7.

19. Solen KA, Mohammad SF, Burns GL, Pantalos GM, Kim J, et al. Markers of thromboembolization in a bovine ex vivo left ventricular assist device model. ASAIO J. 1994;40:M602-8.

20. Wagner WR, Johnson PC, Kormos RL, Griffith BP. Evaluation of bioprosthetic valve-associated thrombus in ventricular assist device patients. Circulation. 1993;88:2023-9.

21. Sliwka U, Lingnau A, Stohlmann WD, Schmidt P, Mull M, Diehl $\mathrm{RR}$, et al. Prevalence and time course of microembolic signals in patients with acute stroke: a prospective study. Stroke. 1997;28: 358-63.

22. Babikian VL, Wijman CA, Hyde C, Cantelmo NL, Winter MR, Baker $\mathrm{E}$, et al. Cerebral microembolism and early recurrent cerebral or retinal ischemic events. Stroke. 1997;28:1314-8.

23. Daffertshofer M, Ries F, Schminke U, Hennerici M. High-intensity transient signals in patients with cerebral ischemia. Stroke. 1997;27: 1844-9.

24. Georgiadis D, Grosset DG, Kelman A, Faichney A, Lees KR. Prevalence and characteristics of intracranial microemboli signals in patients with different types of prosthetic cardiac valves. Stroke. 1994;25:58792.

25. Deklunder G, Roussel M, Lecroart JL, Prat A, Gautier C. Micro- emboli in cerebral circulation and alteration of cognitive abilities in patients with mechanical prosthetic heart valves. Stroke. 1998;29: 1821-6.

26. Infeld B, Bowser DN, Gerraty RP, Voukelatos J, Grigg L, Mitchell PJ, et al. Cerebral microemboli in atrial fibrillation detected by transcranial Doppler ultrasonography. Cerebrovasc Dis. 1996;6:339-45.

27. Nabavi DG, Arato S, Droste DW, Schulte-Altedorneburg G, Kemeny $\mathrm{V}$, Reinecke $\mathrm{H}$, et al. Microembolic load in asymptomatic patients with cardiac aneurysm, severe ventricular dysfunction, and atrial fibrillation: clinical and hemorheological correlates. Cerebrovasc Dis. 1998; 8:214-21.

28. Siebler M, Sitzer M, Rose G, Steinmetz H. Cerebral microembolism and the risk of ischemia in asymptomatic high-grade internal carotid artery stenosis. Stroke. 1995;26:2184-6.

29. Valton L, Larrue V, Arrue P, Geraud G, Bes A. Asymptomatic cerebral embolic signals in patients with carotid stenosis. Correlation with appearance of plaque ulceration on angiography. Stroke. 1995; 26:813-5.

30. Eicke BM, von Lorentz J, Paulus W. Embolus detection in different degrees of carotid disease. Neurol Res. 1995;17:181-4.

31. Markus HS, Thomson N, Brown MM. Asymptomatic cerebral embolic signals in symptomatic and asymptomatic carotid artery disease. Brain. 1995;118:1005-11.

32. Nabavi DG, Georgiadis D, Mumme T, Schmid C, Mackay TG, Scheld $\mathrm{HH}$, et al. Clinical relevance of intracranial microembolic signals in patients with left ventricular assist devices: a prospective study. Stroke. 1996;27:891-6.

33. Scheld HH, Hammel D, Schmid C, Weyand M, Deng M, Mollhoff T, et al. Beating heart implantation of a wearable Novacor left-ventricular assist device. Thorac Cardiovasc Surg. 1996;44:62-6.

34. Georgiadis D, Goeke J, Hill M, Konig M, Nabavi DG, Stogbauer F, et al. A novel technique for identification of Doppler microembolic signals based on the coincidence method. Stroke. 1996;27:683-6.

35. Ringelstein EB, Droste DW, Babikian VL, Evans DH, Grosset DG, Kaps M, et al. Consensus on microembolus detection by TCD. International Consensus Group on Microembolus Detection. Stroke. 1998; 29:725-9.

36. Consensus Committee of the Ninth International Cerebral Hemodynamic Symposium. Basic identification criteria of Doppler microembolic signals. Stroke. 1995;26:1123.

37. DeLong ER, DeLong DM, Clark-Pearson DL. Comparing the areas under two or more correlated receiver operating characteristic curves: a nonparametric approach. Biometrics. 1988;44:837-45.

38. Schmid C, Wilhelm M, Rothenburger M, Nabavi D, Deng MC, Hammel D, et al. Effect of high dose platelet inhibitor treatment on thromboembolism in Novacor patients. Eur J Cardiothorac Surg. 2000;17:331-5.

39. Gaunt ME, Ratliff DA, Martin PJ, Smith JL, Bell PRF, Naylor AR. On-table diagnosis of incipient carotid artery thrombosis during carotid endarterectomy by transcranial Doppler scanning. J Vasc Surg. 1994;20:104-7.

40. Kaps M, Hansen J, Weiher M, Tiffert K, Kayser I, Droste DW. Clinically silent microemboli in patients with artificial prosthetic aortic valves are predominantly gaseous and not solid. Stroke. 1997;28: $322-5$.

41. Markus HS, Droste DW, Brown MM. Detection of asymptomatic cerebral embolic signals with Doppler ultrasound. Lancet. 1994;343: 1011-2.

42. Notzold A, Droste DW, Hagedorn G, Berndt S, Kaps M, Graf B, et al. Circulating microemboli in patients after aortic valve replacement with pulmonary autografts and mechanical valve prostheses. Circulation. 1997;96:1843-6.

43. Goertler M, Baeumer M, Kross R, Blaser T, Lutze G, Jost S, et al. Rapid decline of cerebral microemboli of arterial origin after intravenous acetysalicylic acid. Stroke. 1999;30:66-9.

44. Droste DW, Hansberg T, Kemeny V, Hammel D, Schulte-Altedorneburg G, Nabavi DG, et al. Oxygen inhalation can differentiate gaseous from nongaseous microemboli detected by transcranial Doppler ultrasound. Stroke. 1997;28:2453-6.

45. Palanchon P, Klinger LJ, Bom N, Dejong N. Emboli characteriza- 
tion using ultrasonic harmonic scattering. Cerebrovasc Dis. 2001; 11:16.

46. Knepper LE, Benjamin H, Eidelman H, Wagner WR. Transcranial doppler detection of emboli with left ventricular assist devices. Stroke. 1996;27:180.
47. Roberts JK, Mohr JPMN, Oz MC. Microembolic signals in patients with left ventricular assist devices. Stroke. 1996;27:1915-6.

48. Potapov EV, Nasseri BA, Loebe M, Kukucka M, Koster A, Kuppe H, et al. Transcranial detection of microembolic signals in patients with a novel nonpulsatile implantable LVAD. ASAIO J. 2001;47:249-53.

\section{Bound volumes available to subscribers}

Bound volumes of The Journal of Thoracic and Cardiovascular Surgery are available to subscribers (only) for the 2003 issues from the Publisher, at a cost of $\$ 134.00$ for domestic, $\$ 165.85$ for Canadian, and $\$ 155.00$ for international subscribers for Vol 125 (January-June) and Vol 126 (July-December). Shipping charges are included. Each bound volume contains a subject and author index and all advertising is removed. The binding is durable buckram with the Journal name, volume number, and year stamped in gold on the spine. Payment must accompany all orders. Contact Mosby, Subscription Customer Service, 6277 Sea Harbor Dr, Orlando, FL 32887, USA; phone 800-654-2452 or 407-345-4000.

Subscriptions must be in force to qualify. Bound volumes are not available in place of a regular Journal subscription. 